\title{
Annealing Effects on Phase Transition of a Thermotropic Liquid Crystalline Copolyesteramide
}

\author{
Youn Cheol KIM and In Jae CHUNG* \\ Department of Chemical Engineering, \\ Korea Advanced Institute of Science and Technology, \\ 373-1 Kusong, Yusong, Taejon 305-701, Korea
}

(Received February 12, 1993)

\begin{abstract}
A new thermotropic liquid crystalline (TLC) copolyesteramide with a phenylhydroquinone derivative was synthesized by a solution polymerization. The annealing effect of the copolyesteramide was investigated by using differential scanning calorimetry, polarized optical microscopy, and X-ray diffraction. The TLC copolyesteramide turned out to have a low melting temperature and a wide nematic range above the melting temperature. Because it had bulky side groups from the main chain, the formation of a three-dimensional order was hindered but it could only be achieved by a long time annealing. The fast crystallization was not observed but mainly the slow process was involved in the crystallization. The Avrami parameter $(n)$ of the copolyesteramide has very low values because of the slow crystallization.
\end{abstract}

KEY WORDS Thermotropic Liquid Crystalline Copolyesteramide / Nematic Texture / Slow Crystallization Process / Annealing /

Recently, there has been a world wide interest in the thermotropic liquid crystalline (TLC) polymers because generally they have excellent mechanical properties such as high modulus and tensile strength. However, these TLC polymers have the disadvantage of high melting temperature, with which the processing is not an easy one. To get the easy processability TLC polymers are needed to be modified structurally in order to lower the melting temperature and to broaden the nematic region between melting and isotropization temperatures. The modified polymers can be processed in the anisotropic nature of flow at a low temperature. One way of modification is attaching bulky side groups to a rigid chain backbone, loosening intermolecular interactions and causing the lack of three dimensional ordering in the polymer bulk.

Several works ${ }^{1-10}$ have reported on the characters of TLC polyesters with the bulky side groups attached to the rigid chain

\footnotetext{
* To whom all correspondence should be addressed.
}

backbone. Of the characters, there are two crystallization processes during the isothermal experiment: A fast crystallization process has been characterized as "solidification", and it occurs during quenching from the anisotropic melt. A slow crystallization process is close to a normal crystallization process but has a very low Avrami parameter ( $n$ ). In TLC polyesteramides, some effects developed by the addition of flexible units and nonlinear links in a main chain were recently suggested. ${ }^{11-13}$ However, they have not been sufficiently studied on the mesophase transition of TLC polyesteramides.

For the study on the mesophase transition, a new TLC copolyesteramide with a phenylhydroquinone derivative was prepared. The effects of annealing on the phase transition of the polymer were investigated by using some characterization methods such as thermal analysis, polarized optical microscopy, X-ray diffraction technique, and so on. 


\section{EXPERIMENTAL}

\section{Materials}

1,4-Bis(4-aminobenzoyloxy)-2-phenylbenzene (ABPHQ- $\mathrm{NH}_{2}$ ) was obtained by a catalytic hydrogenation of 1,4-bis(4-nitrobenzoyloxy)-2-phenylbenzene (ABPHQ- $\mathrm{NO}_{2}$ ) in the presence of Raney nickel. ABPHQ- $\mathrm{NO}_{2}$ was prepared from $p$-nitrobenzoyl chloride and phenylhydroquinone by a Schotton-Baumann type reaction in the cold mixture of tetrachloroethane and pyridine. Then, ABPHQ$\mathrm{NO}_{2}$ was dissolved in $\mathrm{N}, \mathrm{N}$-dimethyl acetamide (DMAc) within the range of $95-105^{\circ} \mathrm{C}$ and was reduced to ABPHQ- $\mathrm{NH}_{2}$ in the autoclave under the high pressure of hydrogen. The data by the elemental analysis in Table I indicate that monomers are almost pure. Chemical structures of the monomers were also confirmed by Fourier transform infrared spectroscopy (FT-IR, Bomem Model MB100-C15) and ${ }^{1} \mathrm{H}$-nuclear magnetic resonance (NMR, Bruker AMX 500) as follows.

For $\mathrm{ABPH}-\mathrm{NO}_{2}$

$-{ }^{1} \mathrm{H}$ NMR (dimethyl sulfoxide- $d_{6}$ in ppm from tetramethylsilane);

Peaks for aromatic rings close to nitro group (8.25-8.50 ppm)

Peaks for aromatic rings close to ester group (8.10-8.20 ppm)

Peaks for aromatic rings between ester groups $(7.10-7.60 \mathrm{ppm})$

-FT-IR (KBr); C = O $\left(1743 \mathrm{~cm}^{-1}\right), \mathrm{C}-\mathrm{O}$

$\left(1254 \mathrm{~cm}^{-1}\right), \quad \mathrm{C}-\mathrm{H} \quad\left(3083 \mathrm{~cm}^{-1}\right), \quad \mathrm{N}-\mathrm{O}$

$\left(1350 \mathrm{~cm}^{-1}\right)$.

For $\mathrm{ABPH}-\mathrm{NH}_{2}$
$-{ }^{1} \mathrm{H}$ NMR (dimethyl sulfoxide- $d_{6}$ in ppm from tetramethylsilane);

Peaks for aromatic rings close to ester group (7.55-7.80 ppm)

Peaks for aromatic rings between ester groups (7.25-7.40 ppm)

Peaks for aromatic rings close to amine group (6.45-6.65 ppm)

Peak for amine $(6.05 \mathrm{ppm})$

-FT-IR (KBr); C $=\mathrm{O}\left(1707 \mathrm{~cm}^{-1}\right), \mathrm{C}-\mathrm{O}$ $\left(1266 \mathrm{~cm}^{-1}\right), \quad \mathrm{C}-\mathrm{H} \quad\left(3230 \mathrm{~cm}^{-1}\right), \quad \mathrm{N}-\mathrm{H}$ $\left(3361 \mathrm{~cm}^{-1}\right)$.

The TLC copolyesteramide with a phenylhydroquinone derivative was synthesized from sebacoyl chloride (SBC, $5.73 \mathrm{~g}, 0.024 \mathrm{~mol}$ ), terephthaloyl chloride $(1.22 \mathrm{~g}, 0.006 \mathrm{~mol})$ and ABPHQ- $\mathrm{NH}_{2}(12.72 \mathrm{~g}, 0.03 \mathrm{~mol})$ by Schotton-Baumann type reaction in a cold mixture of DMAc with $5 \mathrm{wt} \%$ of $\mathrm{LiCl}^{12}$ The structure of the copolyesteramide was confirmed by the FT-IR as shown in Figure 1. This figure

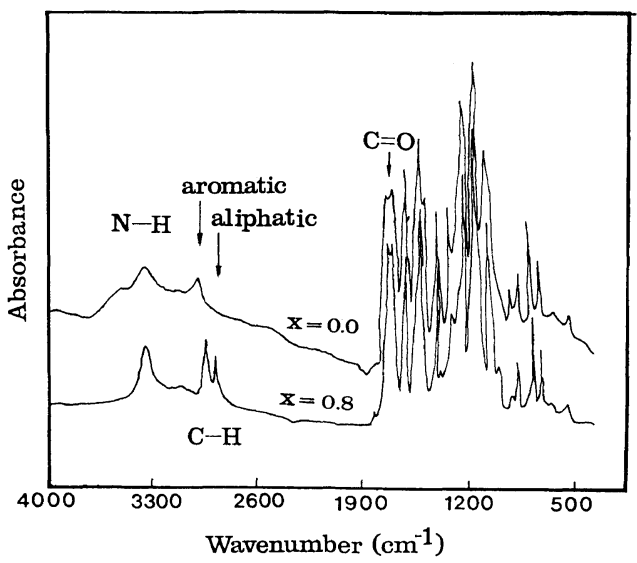

Figure 1. FT-IR spectra for the copolyesteramide and homopolyesteramide.

Table I. Results of elemental analysis for the monomers

\begin{tabular}{|c|c|c|c|c|c|c|c|c|}
\hline \multirow{2}{*}{ Monomer } & \multirow{2}{*}{ Formula } & \multicolumn{3}{|c|}{ Experimental $^{\mathrm{a}}$} & \multicolumn{3}{|c|}{ Calculated $^{\mathbf{a}}$} & \multirow{2}{*}{$\frac{\text { Yield }}{\%}$} \\
\hline & & $\mathrm{C}$ & $\mathrm{H}$ & $\mathrm{N}$ & $\mathrm{C}$ & $\mathrm{H}$ & $\mathrm{N}$ & \\
\hline ABPHQ-NO & $\mathrm{C}_{26} \mathrm{H}_{16} \mathrm{O}_{8} \mathrm{~N}_{2}$ & 64.4 & 3.28 & 5.75 & 64.5 & 3.31 & 5.79 & 73.2 \\
\hline ABPHQ-NH & $\mathrm{C}_{26} \mathrm{H}_{20} \mathrm{O}_{4} \mathrm{~N}_{2}$ & 73.5 & 4.70 & 6.57 & 73.6 & 4.72 & 6.60 & 93.2 \\
\hline
\end{tabular}

a Weight-basis. 
compares the copolyesteramide prepared with the homopolyesteramide without SBC unit. The aliphatic C--H peak in the infrared spectrum is appeared at near $2900 \mathrm{~cm}^{-1}$ for the copolyesteramide. It is recognized that the copolyesteramide has the adequate structure with aliphatic unit as expected. Therefore, the synthesized copolyesteramide may have the following structures.
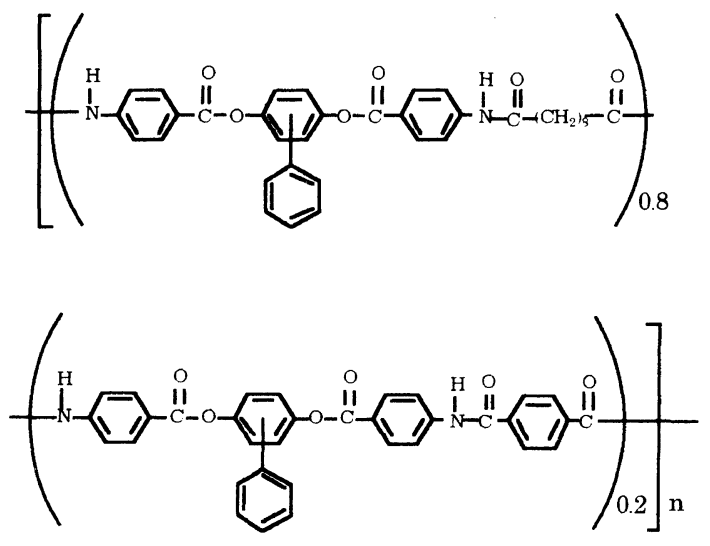

Through the ${ }^{1} \mathrm{H}$ NMR (dimethyl sulfoxide- $d_{6}$ in ppm from tetramethylsilane) technique for the copolyesteramide as shown in Figure 2, the mole ratios of 0.8 and 0.2 in the above structure was nearly identified by the peak area ratios between the aromatic proton and the aliphatic proton as 0.83 and 0.17 , respectively. Various polyesteramides were synthesized. But the copolyesteramide with the above mole ratio was selected because it had the wide nematic range.

\section{Measurements}

Wide-angle X-ray diffraction (WAXD) pattern was measured by an X-ray generator (Rigaku Co.). The point focus beam was monochromatized by using $\mathrm{Cu}-K_{\alpha}$ target with a graphite crystal. The scan speed was fixed at $4^{\circ}$ per min. Quenched samples for X-ray analysis were prepared by immersing the polymer melts in a liquid nitrogen. Specimen for X-ray fiber diagrams were also prepared by making

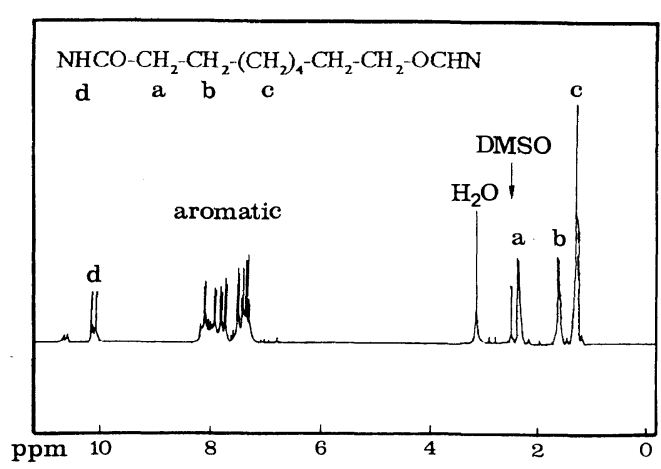

Figure 2. ${ }^{1} \mathrm{H}-\mathrm{NMR}$ spectrum with DMSO (dimethyl sulfoxide) as a solvent for the copolyesteramide. The chemical structure represented in the figure is only for the aliphatic part.

a bundle of 50 fibers. The fibers were prepared by spinning the polymer through a capillary rheometer (Instron Model 3211, $L / D=40$, $D=0.1235 \mathrm{~cm})$ at $280^{\circ} \mathrm{C}$ with the draw ratio (take-up speed/extrusion speed) of about 50 . The $d$-spacings were calibrated with silicon powder (325-mesh size).

DSC measurement was carried out with du Pont 910 thermal analyser to study both non-isothermal and isothermal transition kinetics. For the isothermal crystallization or annealing experiments, the following thermal history was applied: the sample was heated to $300^{\circ} \mathrm{C}$ in scan rate of $20^{\circ} \mathrm{C} \mathrm{min}^{-1}$, held for $3 \mathrm{~min}$, quenched to $100^{\circ} \mathrm{C}$ by using a liquid nitrogen, and heated to a fixed temperature $\left(T_{\mathrm{a}}\right)$ for the isothermal test and remained for a certain period of annealing time $\left(t_{\mathrm{a}}\right)$.

The photographic observation was also carried out by using a cross polarized light microscope (Carl Zeiss Laborlux 12 Pols) with a heating stage and an automatic camera. The heating rate was controlled by about $20^{\circ} \mathrm{C}$ $\min ^{-1}$. The film sample for the polarized optical microscopy was prepared from the solution of DMAc with $2 \mathrm{wt} \%$ of the copolyesteramide. The film thickness was controlled in the range of $5-10 \mu \mathrm{m}$. 


\section{RESULTS AND DISCUSSION}

\section{Thermal Behavior and Liquid Crystalline Texture}

As shown in Figure 3, the copolyesteramide shows no weight loss until reaching $400^{\circ} \mathrm{C}$ and is considered to be a thermally stable polymer. This temperature represents the upper temperature limit for the heating and cooling cycles used in the determination of the thermal transition. Comparing the two heating thermograms as shown in this figure, the melting temperature $\left(T_{\mathrm{m}}\right)$ corresponding to the second peak in the heating curve shows a lower value for the second heating than that for first heating due to the existence of a strong steric hindrance in molecular packing of the copolyesteramide in the cooling scan. The exothermic peak area in the cooling scan (rate $=10^{\circ} \mathrm{C} \mathrm{min}^{-1}$ ) represents a very low value on the same reason. This phenomenon has been reported for various polyesters. . $^{74,15}$

The glass transition of the copolyesteramide occurs at $169^{\circ} \mathrm{C}$ in both cases of first and second heating scans. From the DSC thermograms, no isotropization temperature is observed, but polarized microscopy (see Figure 4) reveals that the copolyesteramide has a nematic mesophase above the melting temperature and that the nematic mesophase is essentially unchanged up to $350^{\circ} \mathrm{C}$ at which dark spots appear in the polarized micrograph. We think that the dark spots might be caused from the degradation of the copolyesteramide at high temperature under the atmospheric condition. This fact shows the possibility that the isotropization temperature would appear above $350^{\circ} \mathrm{C}$. Typically, liquid crystalline patterns with nematic textures at 280 and $350^{\circ} \mathrm{C}$ in the heating scan $\left(\right.$ rate $=20^{\circ} \mathrm{Cmin}^{-1}$ ) were appeared as shown in Figures 4(a) and 4(b). On the other hand, Figure 4(c) shows a nematic texture of the sample cooled with the rate of $20^{\circ} \mathrm{C} \mathrm{min}^{-1}$ to $220^{\circ} \mathrm{C}$ from $300^{\circ} \mathrm{C}$. The sample was further annealed for $10 \mathrm{~min}$ at $220^{\circ} \mathrm{C}$ as shown in Figure 4(d) which represents the

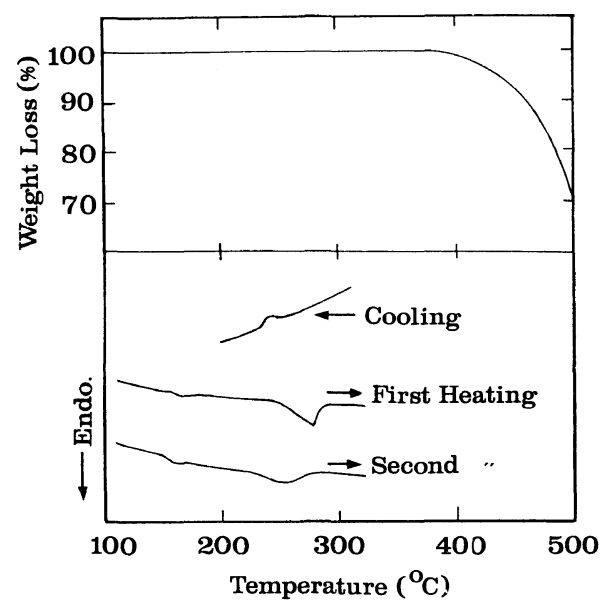

Figure 3. Thermogravimetric result and DSC thermogram of the copolyesteramide (heating rate is $20^{\circ} \mathrm{C} \mathrm{min}^{-1}$ and cooling rate $10^{\circ} \mathrm{Cmin}^{-1}$ ).

keeping of the nematic texture. This result suggests that no crystallization is generated by cooling process $\left(\right.$ rate $=20^{\circ} \mathrm{C} \mathrm{min}^{-1}$ ) due to the steric hindrance of the copolyesteramide.

Figure 5 shows exothermic peaks of the copolyesteramide for different cooling rates. At the cooling rate of $20^{\circ} \mathrm{Cmin}^{-1}$, there is no evidence of forming a crystalline phase, and no melting transition is confirmed on the reheating curve even though it is not presented here. This observation indicates that a fast crystallization process does not occur during the cooling process. As the cooling rate decreases, the crystallization peak becomes more apparent and crystallization temperature becomes higher. It is recognized from this fact that a slow process occurs in the copolyesteramide crystallization allowing a long time to crystallize. The copolyesteramide does not suffer the two-step crystallization processes reported by Cheng et $a l .{ }^{3}$ and Butzbach et al., ${ }^{16}$ but only the slow crystallization process. This fact can be explained by the results shown in Figure 6 and 7. In Figure 6, the effect of annealing time at $T_{\mathrm{a}}=220^{\circ} \mathrm{C}$ is shown. The sample quenched from the nematic melt at $300^{\circ} \mathrm{C}$ does not show the melting endothermic peak when it is reheated from $100^{\circ} \mathrm{C}$ without the annealing. As 

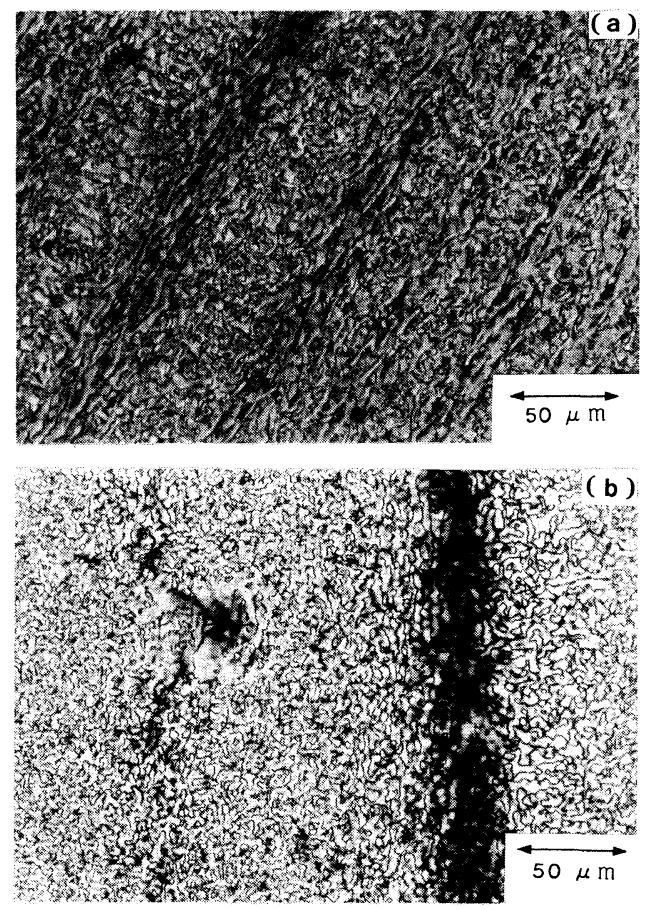
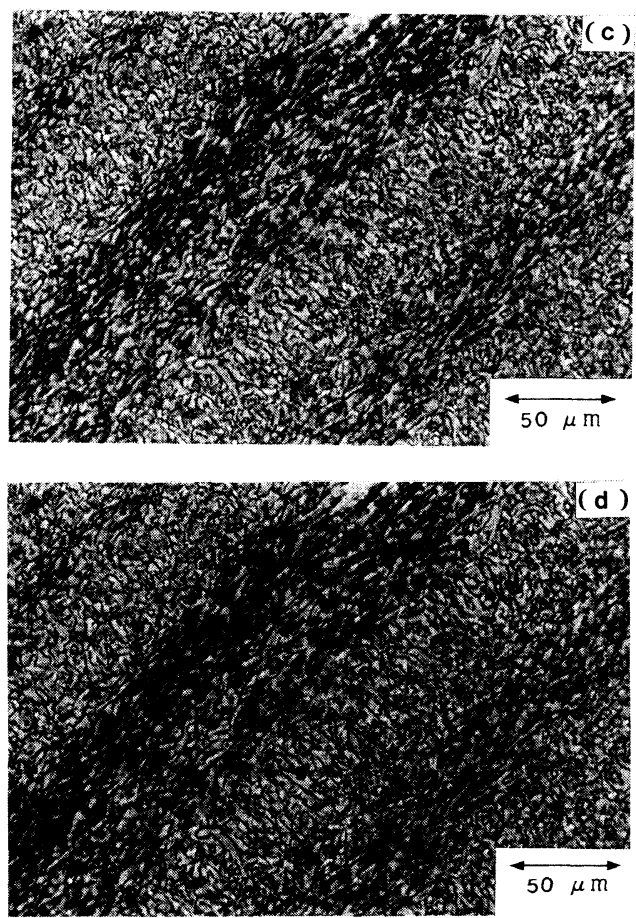

Figure 4. Polarized optical micrographs of the copolyesteramide (a) $280^{\circ} \mathrm{C}$ and (b) $350^{\circ} \mathrm{C}$ in the heating scan (rate $=20^{\circ} \mathrm{C} \mathrm{min}^{-1}$ ), and (c) $220^{\circ} \mathrm{C}$; just after cooling $\left(\right.$ rate $=20^{\circ} \mathrm{C} \mathrm{min}^{-1}$ ) from $300^{\circ} \mathrm{C}$ (d) annealed sample at $220^{\circ} \mathrm{C}$ for $10 \mathrm{~min}$.

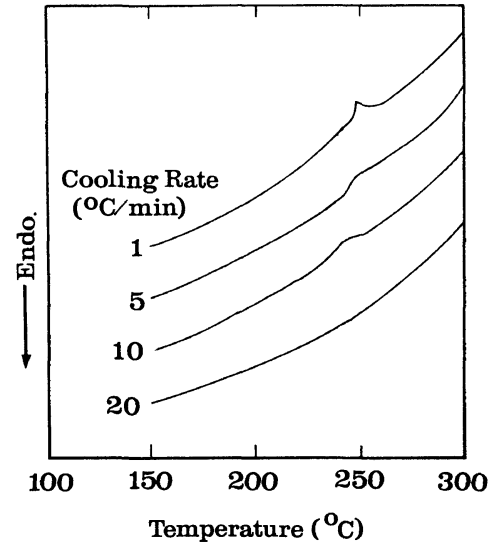

Figure 5. Typical DSC thermograms as a function of cooling rate.

the annealing period at $220^{\circ} \mathrm{C}$ becomes longer, the melting endothermic peak becomes higher shifting toward a higher temperature. As the annealing temperature below $255^{\circ} \mathrm{C}$ (the

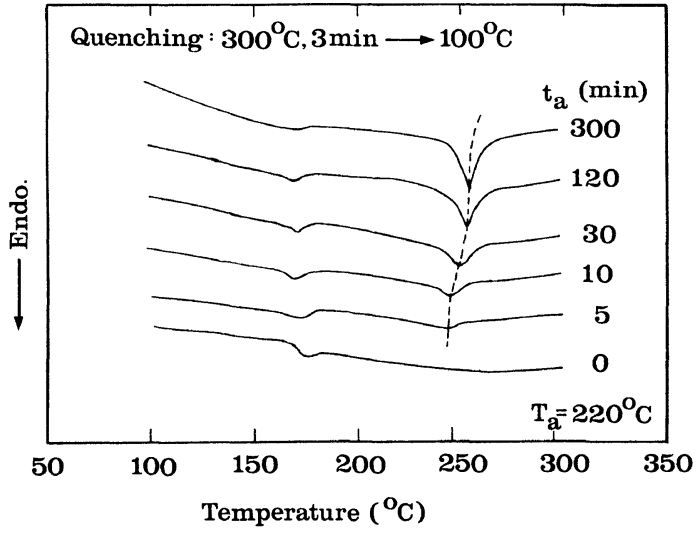

Figure 6. DSC heating thermograms of the copolyesteramide at $220^{\circ} \mathrm{C}$ at different annealing time (heating rate $20^{\circ} \mathrm{C} \mathrm{min}^{-1}$ ).

transition temperature of metastable equilibrium state) increases, the melting temperature increases and the amount of heat of fusion 


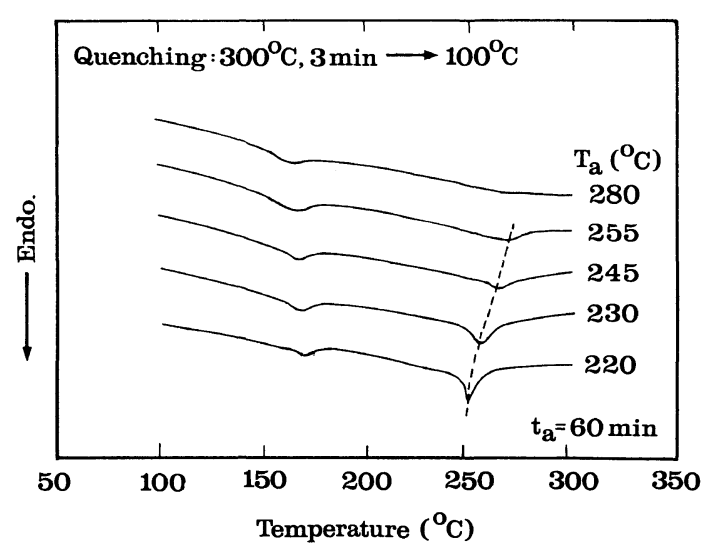

Figure 7. DSC heating thermogram of the copolyesteramide at $t_{\mathrm{a}}=60 \mathrm{~min}$ at different temperatures (heating rate $20^{\circ} \mathrm{C} \mathrm{min}^{-1}$ ).

decreases as shown in Figure 7. The fact that the melting temperature increases with the annealing time could explain that the slow crystallization process might lead to more ordered structures at higher crystallization temperatures. ${ }^{17}$ However, the annealing above $255^{\circ} \mathrm{C}$ is not effective for the crystallization and no peak is observed. Since the morphological change is not observed through the polarized microscopy (see Figure 4) and a slow crystallization is confirmed from Figure 6, the crystallization may take place in a fine and microscopic scale.

Figure 8 shows the change of inherent viscosity with annealing times. The inherent viscosity of the copolyesteramide was measured by using Cannon-Fenske viscometer with $0.5 \mathrm{dlg}^{-1}$ solution in DMAc containing $5 \mathrm{wt} \%$ of $\mathrm{LiCl}$ at $30^{\circ} \mathrm{C}$. As the annealing time increases, the inherent viscosity increases from 0.57 to $0.66 \mathrm{dlg}^{-1}$. In order to investigate the effect of molecular weight on thermal behavior with the increase of annealing time, two samples having the inherent viscosity of 0.57 and $0.66 \mathrm{dl} \mathrm{g}^{-1}$ were heated to $300^{\circ} \mathrm{C}$, quenched to $100^{\circ} \mathrm{C}$, and annealed at $220^{\circ} \mathrm{C}$ for $30 \mathrm{~min}$. They have almost no difference in the amount of heat of fusion and the transition temperature with the data of $7.8 \mathrm{~J} \mathrm{~g}^{-1}$ and $251^{\circ} \mathrm{C}$ for the

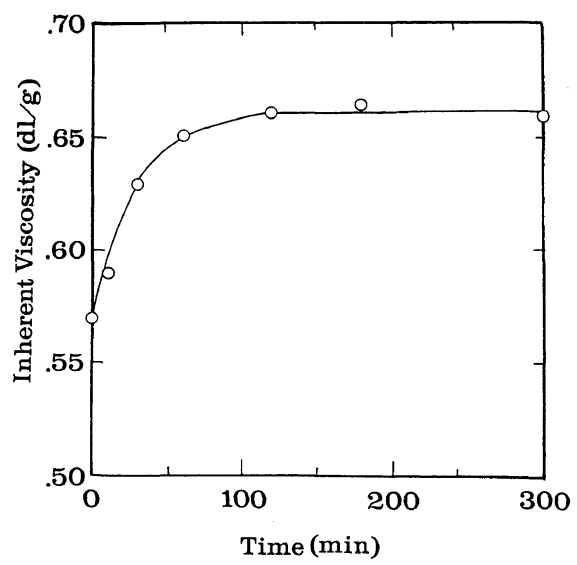

Figure 8. Effect of molecular weight (inherent viscosity) as a function of annealing time.

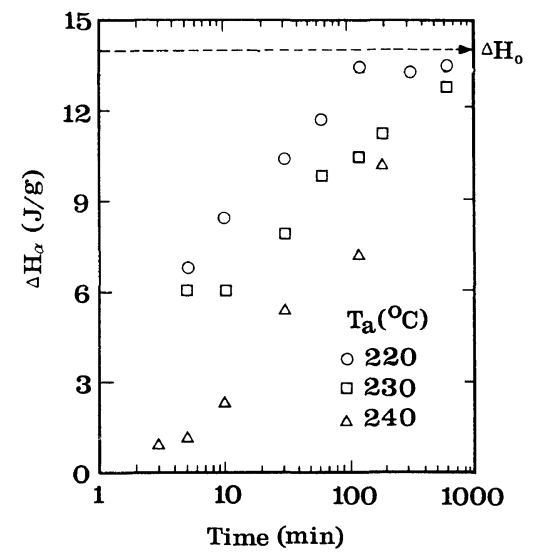

Figure 9. Relationship between $\Delta H_{\mathrm{a}}$ and $\ln t_{\mathrm{a}}$ at different isothermal temperatures for the copolyesteramide.

sample of $0.57 \mathrm{dl} \mathrm{g}^{-1}$ and $7.9 \mathrm{~J} \mathrm{~g}^{-1}$ and $251.7^{\circ} \mathrm{C}$ for the sample of $0.66 \mathrm{dl} \mathrm{g}^{-1}$. We suppose that the annealing time affects the slow crystallization process much more than the molecular weight.

Figure 9 shows the relationship between the amount of heat of fusion $\left(\Delta H_{\alpha}\right)$ and the annealing time $\left(\ln t_{\mathrm{a}}\right)$ at three different temperatures. Since it takes very long time to reach the final stage of crystallization, maximum $600 \mathrm{~min}$ is allowed to remain at an annealing temperature. To obtain the amount of heat $\left(\Delta H_{0}\right)$ at the metastable equilibrium 


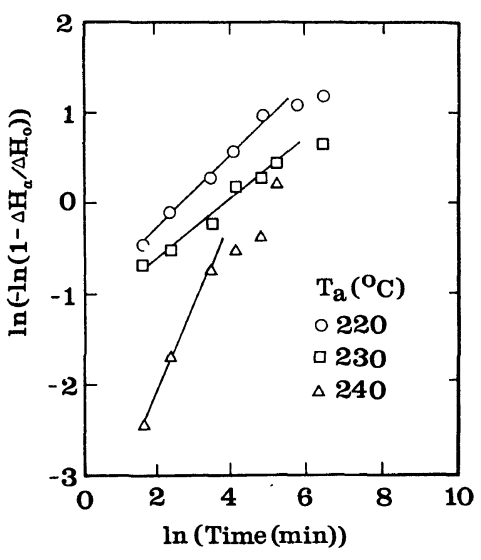

Figure 10. Avrami plot for the copolyesteramide as function of annealing time.

Table II. Avrami parameters of the slow crystallization kinetics of this copolyesteramide

\begin{tabular}{ccc}
\hline Temp $/{ }^{\circ} \mathrm{C}$ & $n$ & $-\ln K$ \\
\hline 220 & 0.35 & 0.89 \\
230 & 0.30 & 1.13 \\
240 & 0.68 & 3.31 \\
\hline
\end{tabular}

state, the extrapolation was made in the plot of $\left(\Delta H_{\alpha}\right)^{-1}$ versus $\left(\ln t_{\mathrm{a}}\right)^{-1}$. The value of $\Delta H_{0}$ could be obtained as $14.02 \mathrm{~J} \mathrm{~g}^{-1}$.

For the calculation of crystallization kinetics, the Avrami equation $\left[1-V_{\mathrm{c}}=\exp \left(-K t^{n}\right)\right]$ can be modified to the form ${ }^{1,18}$

$$
1-\frac{\Delta H_{\alpha}\left(T_{\mathrm{a}}, t_{\mathrm{a}}\right)}{\Delta H_{0}}=\exp \left[-K\left(T_{\mathrm{a}}\right) t_{a}^{n}\right]
$$

where $V_{\mathrm{c}}$ is the crystallinity based on volume fraction and $K\left(T_{\mathrm{a}}\right)$ the nucleation coefficient depending on temperature. Figure 10 shows the relationship between $\ln \left[-\ln \left(1-\Delta H_{\alpha} / \Delta H_{0}\right)\right]$ and $\ln \left(t_{\mathrm{a}}\right)$, and Table II represents the calculated Avrami parameters $n$ and $K\left(T_{\mathrm{a}}\right)$ for the copolyesteramide crystallized at different temperatures. Since the copolyesteramide has low values of $n(0.3-0.7)$ in Table II, it can be interpreted as a slow crystallization similary to (hydroxybenzoic acid)/(hydroxynaphthoic acid) copolymers. ${ }^{1}$

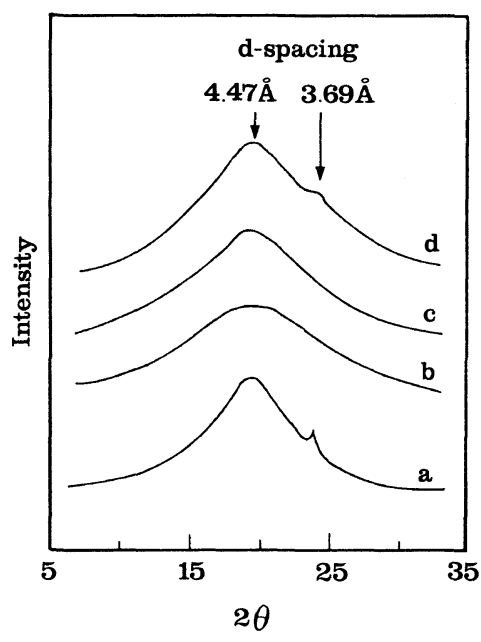

Figure 11. Set of WAXD patterns of different isothermal times for the copolyesteramide quenched from its nematic melt and crystallized at $220^{\circ} \mathrm{C}$. All curves are smoothed. (a) original sample and (b) rapid quenched sample from $300^{\circ} \mathrm{C}$, and (c) $30 \mathrm{~min}$ and (d) $300 \mathrm{~min}$ for annealed sample at $220^{\circ} \mathrm{C}$.

\section{Phase Behavior in WAXD Measurements}

$\mathrm{X}$-Ray diffraction measurements were used to characterize qualitatively the relative three dimensional order of the copolyesteramide before and after annealing. Figure 11 shows the effects of annealing on equatorial WAXD profile of the copolyesteramide. The untreated sample shows two peaks at $2 \theta=19$ (its Bragg spacing is $d=4.47 \AA)$ and $24(d=3.69 \AA)$. The sample quenched from $300^{\circ} \mathrm{C}$ shows no peak at $d=3.69 \AA$ but the only peak at $d=4.47 \AA$. This results suggest that no three-dimensional order is generated by rapid cooling process. As the annealing time increases, the diffraction peak at $d=3.69 \AA$ reappears and the intensity of diffraction peak at $d=4.47 \AA$ also increases slightly.

Figure 12 shows the effects of annealing on the equatorial WAXD pattern for the copolyesteramide. For the sample annealed at $220^{\circ} \mathrm{C}$, higher degree of orientation becomes apparent from the high concentration of the equatorial diffractions. The diffraction at $d=4.47 \AA$ also slightly shift toward a higher 


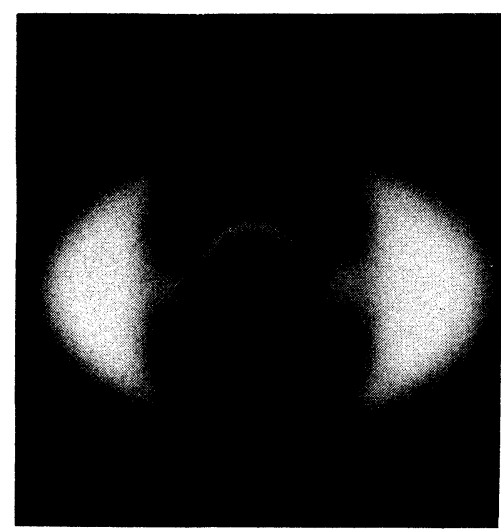

(a)

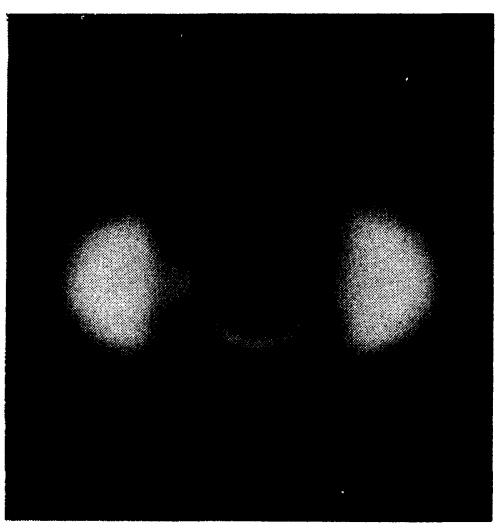

(b)

Figure 12. Wide angle $\mathrm{X}$-ray diffraction photographs of the copolyesteramide fibers with the draw ratio of 20: (a) asextruded and (b) annealed at $220^{\circ} \mathrm{C}$.

Bragg angle. In order to observe weak diffraction spots at meridional direction in detail, the exposure time was prolonged for $10 \mathrm{~min}$ and three diffractions were observed along the meridional direction as shown in Figure 13. These results indicate that the three dimensional order is formed for the slow crystallization process (annealed form) due to the existence of a strong steric hindrance in molecular packing.

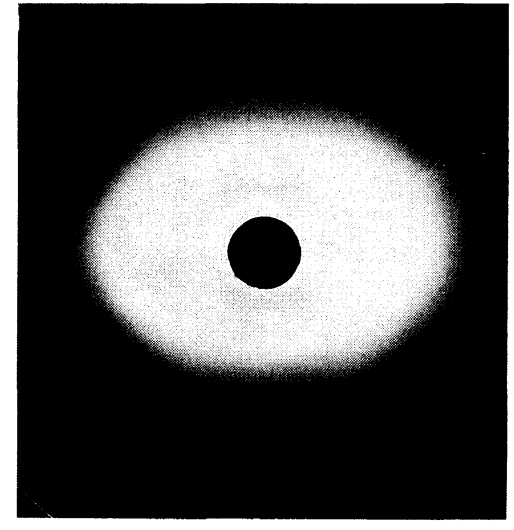

(a)

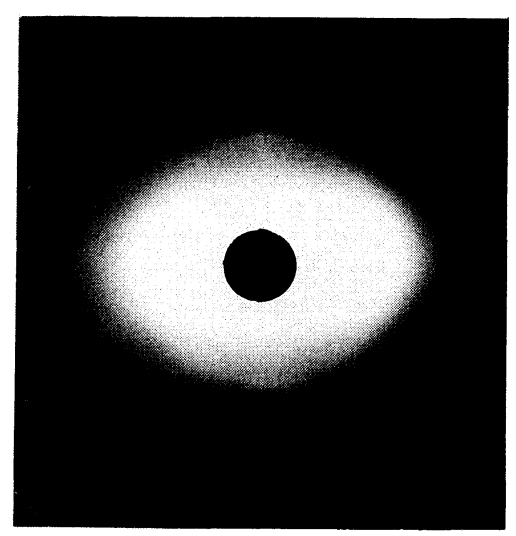

(b)

Figure 13. The same fiber diagram as in Figure 11 but using a prolonged exposure time.

\section{CONCLUSION}

The copolyesteramide prepared in this work shows a nematic texture above melting temperature and a wide nematic range. Owing to the supercooling effect of the polymer, a nematic texture is well preserved at the much lower temperature than the melting point. At a metastable equilibrium state between glass transition temperature and melting point, the slow crystallization process is influenced by annealing time and annealing temperature. From the Avrami equation, the values of Avrami parameter $(n)$ are in the range between 
0.3 and 0.7. Above the melting temperature, however, the annealing time has no effect on slow crystallization process.

Acknowledgment. The authors thanks the Ministry of Science and Technology of Korea for the partial financial support through the Grant-in-Aid (NN06400).

\section{REFERENCES}

1. S.Z.D. Cheng, Macromolecules, 21, 2475 (1988).

2. P. Driscoll, K. Fujiwara, T. Masuda, A. Furukawa, and R. W. Lenz, Polym. J., 20, 351 (1988).

3. S. Z. D. Cheng, R. L. Johnson, A. Zhang, and Z. Zhou, Macromolecules, 22, 4240 (1989).

4. P. Driscoll, K. Fujiwara, T. Masuda, A. Furukawa, and R. W. Lenz, and S. Bhattacharya, Polym. J., 22, 609 (1990).

5. S. R. Rojstaczer and R. S. Stein, Macromolecules, 23, 4863 (1990).

6. M. H. B. Skovby, C. A. Heilmann, and J. Kops, Am.
Chem. Soc., Symp. Ser., 435, 46 (1990).

7. J. del Pino, C. M. Rocha, M. A. Gomez, and J. G. Fatou, Makromol. Chem., 193, 2251 (1992).

8. V. N. Tsuetkov, S. V. Bushin, and L. N. Andreeva, Eur. Polym. J., 28, 955 (1992).

9. H. R. Kricheldorf and F. Ruhser, Polymer, 33, 2431 (1992).

10. V. Tsukruk, Polymer, 33, 2605 (1992).

11. D. Sek, A. Wolinska, and H. Janeczek, J. Polym. Mater., 3, 225 (1986).

12. S. M. Aharoni, Macromolecules, 21, 1941 (1988).

13. T. Uryu, J. C. Song, and J. Kato, Polym. J., 21, 409 (1989).

14. W. Volksen, J. R. Lyerla, Jr., J. Economy, and B. Dawson, J. Polym. Sci., Polym. Chem. Ed., 21, 2249 (1983).

15. M.-Y. Cao and B. Wunderlich, J. Polym. Sci., Polym. Phys. Ed., 23, 521 (1985).

16. G. D. Butzbach, J. H. Wendorff, and H. J. Zimmermann, Polymer, 27, 1337 (1986).

17. M. R. Kamal, O. Khennache, and S. K. Goyal, Polym. Eng. Sci., 29, 1089 (1989).

18. L. Mandelkern, "Crystallization of Polymers," McGraw-Hill, New York, 1964. 